\title{
LRMSC Grade 5, Skin
}

National Cancer Institute

\section{Source}

National Cancer Institute. LRMSC Grade 5, Skin. NCI Thesaurus. Code C121174.

Death directly related to radiation late effects. 